\title{
Ethno-Cultural and Religious Grounds for Cognition and Education
}

\author{
Mustafa Bilalov \\ Daghestan State University \\ Makhachkala, Russia \\ E-mail:mibil@mail.ru
}

\begin{abstract}
The article, on the basis of "cognitive culture" concept, considers the influence of ethno-cultural and religious conscience on the peculiarities of cognitive and educational activity of people from North Caucasus and Daghestan. At the same time tendencies of spiritual life of the peoples of the republic are compared with postmodernist orientation in modern culture, as well as the revealing of common and opposite vectors in their development.
\end{abstract}

Keywords-cognition; education; ethnic and cultural grounds; cognitive culture

\section{INTRODUCTION}

The tendencies of the last century in cognition as a whole and, particularly, in science, revealed their remarkable cultural dependence, as well as the penetration of cultural peculiarities into all the elements: a subject, an object, the means, methods and norms, patterns and ideals, theoretic results and final practical results. Culture as a whole including all its different types and forms, such as material, spiritual, elite, mass, public and counter-public, traditional and industrial (postindustrial), eastern and western, religious and ethnic, country-side and urban, as well as many variants of sub-cultural layers (men, women, and children's 'youth') influences modern cognition. However, not all the components and functions of culture are equally effective in this influence - some have an impact on cognition directly, while others do so indirectly. Such functions as psychological relaxation, recreational, esthetic, etc. are less important for cognitive action than world-estimating, methodological, orienting functions. Such components of culture as social roles and statuses or social institutions are less important for cognition than a way of thinking or living that involves values, skills, methods etc.

In other words, not all culture really determines cognition (and, consequently, education); that is why the level of culture, which leads to the changes in cognitive activity and which is the reason of all the substantial and necessary processes, can be called cognitive culture. It crosses with all the above-mentioned types, forms and kinds of culture and provides many specific features of cognitive culture. Being a general, specific part of many types, forms and kinds of culture, cognitive culture accumulates the traditions, norms, and ideals of both commonplace and scientific cognition. It is not reduced only to cognitive aspects of cognition, but also comprises reflections of social factors of the existence of this subject. The sphere of existence of all the cognitive culture is culture, with a bigger part of certain cognitive activity.

\section{Cognitive CUlture, Its PeCuliarities AND TyPes}

To comprehend the "cognitive culture" concept one needs to study many social and humanitarian sciences (especially psychology) and such a multidisciplinary character of cognitive culture demands its philosophic interpretation. A number of categories also are explained from a philosophic point of view, that's why we can speak of philosophy of cognition, philosophy of knowledge, philosophy of verity, etc. The "cognitive culture" concept also fixes an access point for cognitive problems far beyond gnoseology and their absorption into the philosophy of cognition. The problem concerning components of cognitive culture and their variety proves that. We can only distinguish the blocks of similar components comprising aspects such as the culture of thinking, methodological culture, traditions of cognition, styles of thinking, etc. Scientific components of cognitive culture are ideals and norms, methods and principles, forms and criteria accepted in sciences. Those of which that have been approved by the scientific society and acquitted themselves by long heuristic effect, make solid systems in the form of cognitive and scientific traditions. Philosophic components of this culture are general methods, principles and other bases of science and cognition, which in one way or another are fixed in eclecticism, metaphysics, dialectics, partially in synergetics and modern postmodernist ideas; one of the main philosophic elements of the contents of cognitive culture is ideological world picture which sometimes gives it a well-seen ideological image. Religion and ethnicity in the cognitive culture also touch upon ways and means, levels and stages, aims and ideals of the creative work of a man: they fix a certain variant of their set, historically formed in religious and ethnic traditions of spiritual production. Classification of cognitive cultures into scientific, philosophic, religious and others is possible only due to domineering all the mentioned elements within it.

The spiritual sphere of a man contains various types, kinds, levels of cognitive culture, which in turn, are determined by these philosophic and scientific traditions, styles of thinking, a methodological arsenal of science, philosophic methods, ethnic mentalities, types of religion, etc. 
In order to distinguish such historical types of cognitive culture as pre-modernist, modernist and postmodernist, we can categorize them using aspects such as religious, ethicnational, philosophic, scientific, gender, etc. For example, to name a few such classifications: Islamic, German, sophistic, natural-science, female, youth, etc.

The contents and essence of modern cognitive culture is influenced by the fact that the spiritual life of society and cognitive activity of a man not only go through the society of information, but also due to the general knowledge of the society, as the subject of it is no longer a former (classic) abstract cognitive subject, but a living multi-leveled being, "restored as a whole man, a knower" [13. P. 584.], after which all the ideas of cognition as an intellect, imagination, and "life experience" change. This circumstance increases connection between culture and cognition, as well as increasing the role of cognitive culture in spiritual life of a mankind. While moving philosophically deeper into the sphere of cognitive culture it is possible to take into account a methodologically important statement by B. Pruzhinin, saying that the peculiarity of a society is not only in widening the scales of implementing the scientific knowledge, but also in the very change of the essence of knowledge due to peculiarities of the cultures, which is determined by the role of sciences [14. P.30]. one more tendency we can speak of is an increasing role of scientific thought together with a decreasing value of philosophic thinking, which began after the decline of classic philosophy (metaphysics).

Globalization has brought to life a huge level of earlier unknown or unimportant cultures, such as national, ethnic, religious, marginal, etc., and demanded their intruding into the world's spiritual creativity, their dialogue and polylog. Many local and private cultures provoked irrationalism, the refusal of a universal mind. As cognitive culture is a part of culture as a whole, it has all of the characteristics and tendencies of the whole culture. Many of them are not constant; they have some certain historic nature and only sporadically define local culture. Not going into details of the problem of variety and the unity of cultures, their specifics and universal stages, we can mark not long ago the working idea of such an evolution in mankind. However, the popularity of the evolutionary approach has recently decreased because of its simplification of a complex and contradicting character of the development of culture. At first, its progressive direction and rationalist character were criticized, as well as its grappling with the mind. The initiative in explaining the cultural phenomena of society was taken by irrationalism in face of freudianism, philosophy of life, pragmatism, assistencialism, etc. Thanks to the efforts of N.Y. Danilevsky, O. Shpengler, L. Levi-Brule, A. Toinby and others, the idea of a universal culture was distorted, the point of view on culture as some local cyclic process had won, and it had its own specifics determined by psychological phenomena such as feelings, emotions, passions, as well as mentality, religion, morals and other non-rational and irrational factors, which diminished the role of the mind in a cultural society to a secondary role. At the same time an information epoch greatly influenced culture as a stage of its postindustrial society, the computing and technological mechanisms for the creation of information and symbols formed the main components of culture.

\section{ETHNIC AND RELIGIOUS IN COGNITIVE CULTURE}

These changes also influenced modern peculiarities of cognitive culture. Both religious and ethnic aspects have changed, especially where it concerns ways and means, levels and steps, aims and ideals of the creative activity of a man. In spheres where in their contents ethnic traditions prevail, they acquire pure national colouring. The next historical form of cognitive culture Следующей исторической формой познавательной культуры are religious forms, first of all, Christian, Buddhistic or Islamic cognitive cultures. Here religious traditions and faith prove the main forms of impacting religious conscience on the contents and essence of the cognition. We spoke above about the influence of cognitive, scientific and philosophic traditions on the image of cognitive culture. Let's consider now the influence of religious traditions and religious faith on cognition.

First of all, in the process of interacting with the social environment and only after gaining some ethnic peculiarities of it's essence, a man (in all stages of his development) can be set on religion. Religion takes over the irrational level of a man's conscience, joining people by faith and unpredictable or undiscovered things in science or cognition rather than by knowledge and way of thinking. But, however, historically cognitive culture has close ties with religious conscience - it is scientifically proven that, for example, Buddhism is organically connected with theory of cognition, though "primary Buddhism is nothing more than unsystematic attempt to criticize the world and cognition. Their scientific development both these contradictory points gained in latest Buddhism (makhayana)... and in renewed brakhmanism..." [21. P. 18]. This is the view of the outstanding Russian scholar of eastern culture, F.I. Shcherbatsky, who is still considered in India as a teacher-guru, who told the Indians Buddha's philosophy. Some general ideas can be found in cognition and Christianity, in cognition and Islam.

Taking into account the fact that a modern science developed exactly from Christian culture, some cognitivists consider it possible to introduce the term "religious epistemology" into philosophy, where it can touch on two key questions: is there in religious statements anything that "could suggest their verity or falseness?" and the question of "true interpretation of Christian precepts by a man" [12. P. 155]. Islam did not lag behind in theoretical and methodological interpretation of world religions either. The researcher of Persian literature, history of Islam and its philosophic traditions Abdol Hossein Zarrinkub supposes that with the beginning of the era of Abbasids "such scientific discipline as usul (methodology) began to form, thus scientific principles for forming rules of Fikh were established. There also was formed a science of kalam, according to which all the debates concerning main principles of faith were logically put and arranged" [9. P. 56]. 
As we often remarked in scientific literature, cognitive culture accumulated cognitive ideas of a dialectal character of cognition, which are fixed in the religious conscience as infinity for knowing the absolute verity, as a differentiation of cognitive activity into sensitive, intelligent, intuitive and other stages. [See detailed: 3]. The idea of complexity and contradiction of cognition makes people be modest in estimations of their knowledge and causes their constant wish for perfection. The important element of cognitive culture, borrowed from religion, is the idea of self-cognition as an important stage and aim of a man's cognition. Religious conscienceness also comprises theoretic and cognitive idea of synthetic character of cognition, the idea of unity of cognitive and estimating cradles. The main unity of religious ideology is faith, and it is fixed in cognitive culture as an inevitable stage and result of cognitive process. Cognitive culture borrows not only positive aspects from religious conscience, but also negative traditions of minimizing the role of mind in cognition, cognitive pessimism, agnosticism, the break between knowledge and practice and others, which are in part the basis for contradictions between philosophy and religion, science and religion, and secular and religious education.

As during historical development the structure of cognitive culture becomes complicated, it is not correct to think that all its elements have a real impact on religious conscience. It is evident, for instance, that formal and logic principles determining the culture of thinking, are not in direct dependence on religion. But such elements of cognitive culture as a way of thinking, traditions, ideals, ways and means, prejudices, really depend on religious conscience very much. There are also many ethnic aspects in cognitive culture and sometimes, religion itself gains an ethnic colouring after being introduced into the culture.

\section{SuFISM As BASIS For COGNITION AND EDUCATION}

Sufism is one of the heretic deviations of Islam and seems to be rather convincing basis for cognition and education. It considers the union of a man and a god as an aim of a man's self-perfection. After deeper investigation, this union turns out to be cognition and what is remarkable, some of the numerous names of Sufism directly connect it with cognitive activity of a man. Sufis are often called cognitivists, wise, esoteric, etc., hinting at their love of mysterious, hidden knowledge, cult rituals, known only by the privileged. Life ideas of Sufis and the reality follow this high purpose, for the state of complete destroying, of "absence" of oneself (fana) is exactly the very knowledge of God, of the complete verity. This trangressive way of a subject out of the borders of normal psychics which is equal to that of universal religious ecstasy, is called by George Batalle, a famous French philosopher, as phenomenological manifestation of trangressive transcensus to Absolute. Really, religious ecstasy is the overcoming of an endless limit, a subject's access beyond the limits of usual, an access to verity, to God. Speaking of religious transgression, connected with ecstatic sensuality, modern philosophy goes deep into a sensual variety of Sufism. In the terms of postmodernism transgression is one more falling out of line process of self-perfection of Sufism, or rather, confirmation of synergetic and abrupt manner of a man's cognition.

Sufism is quite contradictory to intellectualism of mutasilits in explanation of a man's cognition, by putting emphasis not in the mental activity of a man, but rather in his irrational, incomprehensive love of cognition of God. In the same time we do not lower ideological richness and cognitive substantiality of Sufism, all the more so, Islam itself being an intellectual religion, loses to Buddhism in its philosophic depth. This can be justified by the character of faith and intuition - basic methods and ways of religious cognition. They have their own specifics in Sufism [see: 4] the faith here is not authoritative, and does not refer to god's confession, but rather, is the result of subjective, suffered and emotionally ecstatic assuredness, the result of individual provision and mystic intuition. In the same time, intuitive concept of religious faith is "less irrational", and even is considered an intellectual branch in the interpretation of religious experience. Meanwhile "the followers of antiintellectual movement try to clear out religious experience from the least manifestations of cognitive activity" [15. P. 120].

Thus, on the one hand, Sufism states the aim of a man's living is achieving the Unity of Being, meaning the union of a man and God; on the other hand, this aim lies in the comprehension of the theoretical grounds of this union, which is the highest cognition. As Rumy, a famous Iranian Sufism poet states, "God has made us to help to understand the verity" [16. P. 193].

The wideness and effectiveness of the influence of Sufism religion and philosophy on the everyday real behavior of people by means of cognitive culture are also determined, to our mind, by its universalism, partially because of its closeness to esoterism and occultism. It is known that in the basis of occultism there are esoterics as a very successful attempt to harmonically and systematically connect philosophic and religious thoughts with scientific ideas. The principles of esoterism are the following: criticism of routine life and culture, belief in existence of another, true reality, convincement that a man must and is able while living to intergrade into this reality (on condition a man should transform his personality, constant intense spiritual work over oneself, altering oneself into another being), recognition of correlation between micro- and macro-space, the importance of mastering all the technics and so on, - they all seem to be philosophic and religious grounds for ecumenism and fundamental traditions of Sufism, its cognitive culture. Occultism and esoterism greatly enriched Sufism both theoretically and ritually.

Irrationalism and mysticism are the most important ecumenist intentions of Sufism. The main advantage of irrationalism is the expanding of the sphere of cognitive abilities by means of leading them beyond the limits of conscience using the unconscious. As for mysticism, it is considered that "the phenomenon of religious mysticism passes through the stages of formation and development of ancient structures of people's self-consciousness, and later is kept as an archetype of mysticism in the structure of 
religious-systemic conscience, like a phenotype". In other words, Sufism focuses at contents' value of the mysterious, as a component of the basis of religion. That is why irrationalism and mysticism, as fundamental acquirements of Sufism are often used as the basis of the union of different cultures; in particular, "mysticism within Christian and Islamic cultures is a special conceptual scheme, a metacultural orientation" [2. P. 73].

Faith and intuition are the forms of mysticism and irrationalism. Their subjective and intellectual character mentioned above, does not change the irrationalism of Sufism. Irrationalism and mysticism are also connected with little speaking, and even silence in Sufism. Silence in Sufism gets a symbolic sense, it is deeply rooted in cognitive aspects, making focus at other ways of existing of a spirit and Sufism ritual practice. Silence plays the role of zikr, the only form of expressing the verity. Admitting that the verity could exist pre-verbally and non-verbally, the Sufis worked out a special language, including hundreds of terms with which they could express the slightest emotions and conceptions having no usual verbal equivalents. That is why the mysterious experience is non-verbal. But if it is transformed by words, it "almost always is just a useless distortion of facts" [20. P. 111]. It uses all the possible variety of meanings of silence, working in interpersonal communications, very specifically adopting them and using their interpretation as applied to spiritual and cognitive acts.

As Sufism and its elements deeply rooted into the social conscience, this could not but effect education and culture. For example, the region of North Caucasus and ghestan. In Daghestan Islamic institutions pay special attention to the moral education of students. They cultivate respect between the students, there are no problems with drug use, alcoholism, smoking, crime. In this respect Islamic institutions in our republic are much higher than secular ones. However, Daghestan system of religious education of Sufi orientation could not on the whole oppose and fight against vakhabits' ideology and in fact lost the battle.

Speaking about negative tendencies in Daghestan education, one can't but mention the problem of "A TeacherStudent", which has its basis in the cognitive relations "subject-object". Who is the true subject of the process of education? How can one avoid authoritative traditions, changing the students into a pure container of knowledge and moral values? How can we transfer from a pupil-recipient and retranslator to an active and studying subject? What place does the pedagogics of cooperation take? How can we place within it the tradition of the separate teaching of boys and girls? Such a circle of problems was solved in traditions of Moslem and later, of Soviet education rather ineffectively. In all the Islamic educational institutions they in general studied texts of the Quran, khadises and developed memory. The researchers also state that the traditional system of Daghestan education was rather conservative, with the domineering of the spirit of religious fanatism and intolerance to others [see about it: 10]. All this shows that a typical student of the Moslem school was very far from an active and thoughtful subject of the cognitive process. Moreover, many negative moments of social and political tension have a rather firm ground in conservatism and dogmas of Moslem education.

\section{ECLECTICISM OF MODERN CULTURE AS A BASIS OF COGNITION AND EDUCATION}

Religious traditions and tendencies as a whole, prevent Daghestan education from joining modern education, while the world nowadays we see complex education allowing to study at different levels within the new teaching paradigm. New educational models should orient at "new pedagogical pattern of education: knowledge - skills - possibilities comprehension - creativity" [1. P. 59]. Fundamental change in the world image in a new millennium suggests the beginning of a new era. It is evident that "the model of education of the XXI century should suffer cardinal changes and should orientate not to the past (conservatism), but to the future (futurism) of a man's civilization, which also changes its paradigm (pattern) of development [18. P. 4]. According to many different experts, the main features of a new paradigm are: the change from a main sensible sign from rationalism to culture; the transfer from a reproductive model of education to a productive humane and culture-oriented model [6. P. 12].

The sense of education within the culture-centric conception of education does not to fill in memory with some information or develop intellect, but rather brings up a "spiritual instinct", which can help an individual find the highest sense of living. In this case the result of education is the spirituality of an individual as an absolute value of a man's life, the grounds for the sole and inner state of a man [8. P. 323]. This conception "supposes taking education as the most important social establishment of cultural exchange; widening the humanitarian score of education by means of harmonious introducing of Russian culture into the educational process; improving the role of education for formation of "culture of life-ability", both psychological and moral, the ability to live in a modern and quickly changing world as the way of getting a new creative personality, a conscientious subject of social and cultural changes; optimal combination of professionalism and universalism; orientation at principles of partnership and social responsibility, at priority of democratic and humane social technologies" [8. P. 324]. It is evident that modern ethnic and cultural grounds for cognition and education in the Northern Caucasian region are far from conceptual components of culture-centric education.

One of the integral components of cognitive culture is scientific rationalism. Their connection is very argumentative. On the one hand, all the educational cultures can be characterized from the point of view of scientific rationalism, but on the other hand, rationalism itself is a result of special scientific and philosophic variants of cognitive culture. But it does not mean that the waterline between science and pseudo-science goes along with rational and irrational cognitive cultures. Besides, cognitive culture is not always only rational or irrational. Even scientific rationalism can comprise within itself both of these features. Postmodern philosophic cognitive culture is irrational not because it denies classic irrationalism, but because it 
contains irrational cognitive abilities of a man, including even many irrational methods, operations and procedures of science.

We do not speak of a well-known historical law, when classic reality is connected with all the possible achievements and success of civilization, was not universal and obligatory for a man's cognition. If "some ethnos does not correlate with modern civilization, and is not profitable from an economic point of view, we can say that from a biological point of view the behavior of the ethnos can't be mistaken" [11. P. 332]. The thing is, in modern culture, mentality is getting stronger and stronger. From the social point of view this behavior is not mistaken either. Today very often tradition shows that "consensus concerning a principle which should be ratified is fed by economic and political. This should be a warning for those who can ignore it" [19. P. 38-39]. According to the whole culture this idea is developed by J. Bodriyare: «In our eclectic culture which is suitable to decline and mixing up of other cultures, nothing is impossible" [5. P. 109].

We suppose that eclectics of culture in Bodriyare's interpretation is not opposite to dialectics, ruining the system as a whole. It is not antagonist combination of opposites, but the joining of tolerant components of culture - myth and science, religion and philosophy, rational and irrational. In this case regional ethno-culture is quite modern as the basis of cognition and education.

\section{CONCLUSION}

Andrew Tarkovsky, who is of Daghestan origin, tried in his works to express the idea of a similarity between rational and irrational in comprehending the world. In his creative works there certainly is a number of elements of oriental culture, as well as some sympathy for an intuitive and mystical comprehension of the world, which lie beyond the limits of the rational mind into the irrational [ see about it: 17].

Remarkable protest against idealization of role of intellect and refined ratio in modern culture, cognition and education is set by postmodernism. One of the noticeable signs of the inner renewal of Western-European reflexive thinking has become the deconstruction offered by Derrida. According to him, it overcomes criticized ways of thinking, "makes a text which it deconstructs a new context", thus getting new impulses for developing a new thinking. «Deconstruction is not forgetting the tradition, but on the contrary, memory of what was forgotten", - as V. Dyakov writes. Derrida himself called deconstruction "a jest of discredit for any europocentrism", it is a pure European product - Europe treats itself as an experienced subject of "radical unlikeness" and in this self-criticism we see a chance for survival for a Western world [7. P. 226]. In such a case development of culture at a world scale is quite adequate to basic grounds of modern cognition and education.

Thus, in spite of all the ethno-cultural and religious obstacles on the basic grounds of modern cognition and education in Northern Caucasus and Daghestan, we can state that there are profitable terms for the region to develop tendencies in culture and in perspectives of world civilization. With the eclectics of culture, it is possible to comprise myths, religion, mystics and other irrational components, which make spiritual existence of the peoples, and make it possible to consider ethnic-cultural and religious life of the ethnos of the region as a rather effective base for modern cognition and education. Eclectics of culture now consisting of tolerant rational and irrational elements, borrowed from both European and oriental spirits, can create a new vector in its development, proper for mankind.

\section{REFERENCES}

[1] I.A. Aleksandrov, "Philosophic conception of higher education: towards new educational models," Philosophy of Education Scientific Journal, No. 5, 2002

[2] A.A. Baranets, Trans-phenomenon of mysticism as cultural phenotype in Christianity and Islam // Christianity and culture. To the 2000 Anniversary of Christianity, P. II, Astrakhan, 2000.

[3] M.I. Bilalov, "The gnosiological ideas in the structure of religious consciousness," M., 2003.

[4] M.I. Bilalov, "The gnosiological ideas in religious consciousness," M., 2003.

[5] Jean Baudrillard, "The Transparency of Evil,” M.: Dobrosvet, 2012.

[6] A.P. Valitskaya, "Culture creative school: concept and model of educational process,” Pedagogika, No. 4, 1998.

[7] A.V. Dyakov, "The philosophy of poststructuralism in France," New York, 2008.

[8] A.S. Zapesotsky, "Education in the humanities and the problems of spiritual safety," Pedagogika, No. 2, 2002.

[9] A.Kh. Zarrinkub, "Islamic civilization,” M., 2004.

[10] G.Sh. Kaimarazov, "Muslim educational system in Dagestan," Islam and Islamic culture in Dagestan, M., 2001.

[11] A.D. Korolyov, "Ethno-confessional experience and search for truth," What is truth? Conference abstracts of the All-Russian research-topractice conference (Makhachkala, September 6-7, 2013), Ed. by Ph.D., prof. M.I. Bilalov, Makhachkala, 2013.

[12] F.V. Lazarev, Bruce A. Little, "The modern epistemology: spirit and challenges," Simferopol, 1999.

[13] L.A. Mikeshina, "The philosophy of cognition. Polemic chapters," M., 2002.

[14] B. Pruzhinin, "Knowledge in contemporary culture," (round-table proceedings), Voprosy Philosofii, No.9, 2012, pp. 3-45.

[15] M. Sergeev, "What is religion? Reflections on the nature of religious experience," Bulletin of the Russian Philosophical Society, No. 4, 2003.

[16] "Sufi. The ascent to truth," M., 2001.

[17] Andrei Tarkovsky, "Captured time," Film art problems, Issue 10, M., 1967.

[18] A. Ursul, A. Romanovich, "World Summit on sustainable development: results, aspirations, perspectives," "Alma Mater" High School Bulletin, No.4, 2003.

[19] Max Horkheimer, Eclipse of reason. To critics of instrumental reason / Max Horkheimer, M.: Kanon+, POOI Rehabilitation, 2011.

[20] Idris Shakh, "Sufism," M., 1994.

[21] F.I. Shcherbatskoi, "The theory of knowledge and logics following the latest Buddhists' teaching," Part 1, Saint Petersburg, 1995. 